\title{
Intervenção fonoaudiológica na Síndrome de Turner: relato de um caso
}

\author{
Speech therapy intervention in Turner Syndrom: case report \\ Intervención de logopedia en Síndrome de Turner: reporte de un caso
}

Recebido: 30/10/2021 | Revisado: 07/11/2021 | Aceito: 10/11/2021 | Publicado: 17/11/2021

\author{
Matheus Francoy Alpes \\ ORCID: https://orcid.org/0000-0001-9617-7668 \\ Universidade de São Paulo, Brasil \\ E-mail: matheus.alpes@usp.br \\ Carla Manfredi dos Santos \\ ORCID: https://orcid.org/0000-0002-2162-0802 \\ Universidade de Sorocaba, Brasil \\ E-mail: carla_usp@yahoo.com.br \\ Patrícia Pupin Mandrá \\ ORCID: https://orcid.org/0000-0002-2926-0354 \\ Universidade de São Paulo, Brasil \\ E-mail: ppmandra@fmrp.usp.br
}

\begin{abstract}
Resumo
O objetivo foi descrever o processo de avaliação e intervenção fonoaudiológica de uma criança com Síndrome de Turner por meio de estudo de caso longitudinal. Foram analisados os documentos arquivados em prontuário eletrônico (anamnese, hipótese diagnóstica, plano terapêutico singular e evoluções clínicas) referentes à avaliação (3 sessões) e terapia fonoaudiológica (17 sessões). Os dados de avaliação inicial evidenciaram déficits nas habilidades comunicativas gerais (vocabulário emissivo e receptivo), com escore abaixo do esperado para a sua faixa etária. Com a intervenção fonoaudiológica, foi evidenciada significativa evolução nestas habilidades e aumento do escore encontrado na avaliação, demonstrando a importância do fonoaudiólogo no atendimento desta população.
\end{abstract}

Palavras-chave: Síndrome de Turner; Fonoaudiologia; Linguagem infantil.

\begin{abstract}
The purpose was to describe the evaluation process and speech therapy intervention of a child with Turner Syndrome through a longitudinal case study. Documents filed in electronic medical records (history, diagnostic hypothesis, unique therapeutic plan and clinical evolution) referring to the assessment ( 3 sessions) and speech therapy (17 sessions) were analyzed. The initial assessment data showed deficits in general communication skills (emissive and receptive vocabulary), with a score lower than expected for their age group. With the speech therapy intervention, a significant evolution in these skills and an increase in the score found in the assessment was evidenced, demonstrating the importance of the speech therapist in the care of this population.
\end{abstract}

Keywords: Turner Syndrome; Speech, language and hearing sciences; Child language.

\section{Resumen}

El objetivo fue describir el proceso de evaluación e intervención logopédica de un niño con Síndrome de Turner a través de un estudio de caso longitudinal. Se analizaron documentos archivados en historia clínica electrónica (historia, hipótesis diagnósticas, plan terapéutico único y evolución clínica) referentes a la valoración (3 sesiones) y logopedia (17 sesiones). Los datos de la evaluación inicial mostraron deficiencias en las habilidades de comunicación general (vocabulario emisor y receptivo), con una puntuación inferior a la esperada para su grupo de edad. Con la intervención logopédica se evidenció una evolución significativa en estas habilidades y un aumento en la puntuación encontrada en la evaluación, demostrando la importancia del logopeda en el cuidado de esta población.

Palabras clave: Síndrome de Turner; Fonoaudiología; Lenguaje infantil.

\section{Introdução}

A Síndrome de Turner (ST) é considerada uma doença rara, decorrente da deleção total ou parcial do cromossomo X. Acomete entre 1:2000 e 1:5000 recénascidas do sexo feminino (Gravholt, Viuff, Brun, Stochholm \& Andersen, 2019). 
O diagnóstico pode ser realizado no período pré ou pós-natal por meio de exame genético (Marzelli, 2011). O tratamento pode envolver uma equipe multiprofissional formada por médicos (geneticista, pediatra, cardiologista, oftalmologista, ginecologista e otorrinolaringologista), psicólogos e fonoaudiólogos (Giagheti, 2004).

As principais características descritas são: face triangular, baixa estatura, baixa implantação capilar, alterações visuais, malformações cardíacas e renais, tórax escavatum (depressão do esterno e costelas à frente do tórax) e amenorreia (Araujo, Galera \& Medeiros, 2010). Alterações referentes à audição (lóbulo proeminente, otite média e perda auditiva do tipo neurosenssorial) (Alves \& Oliveira, 2014) e estruturas e/ou funções orofaciais (má-oclusão dentária e palato ogival) são relatadas (Oliveira, Freiberger, Fernandes, Marcelino, da Rosa \& Correa, 2005).

A heterogeneidade genética é responsável por variações no fenótipo cognitivo desses indivíduos, especialmente em habilidades verbais e não-verbais (Antunes, Julio-Costa \& Haase, 2015). Resultados em testes de QI verbal e nos subtestes de semelhanças verbais, compreensão verbal e vocabulário estiveram dentro da expectativa normativa nesta população (Temple, 2002).

De acordo com a literatura recente não foram descritas significativas alterações em habilidades linguísticas e/ou deficiência intelectual em pacientes com ST (Temple, 2002; Lee, Bennett, Howell \& Tartaglia, 2019; Kruzka \& Silberbach, 2019), e, por isso, poucos estudos abordam diretamente a atuação fonoaudiológica nestes casos, especialmente na área da linguagem.

Sendo assim, o objetivo deste estudo foi descrever o processo de avaliação e intervenção fonoaudiológica de uma criança com diagnóstico de Síndrome de Turner atendida em um serviço público média complexidade.

\section{Metodologia}

O relato de caso clínico foi aprovado pelo Comitê de Ética do Hospital das Clínicas da Faculdade de Medicina de Ribeirão Preto (HCFMRP-USP) sob número 1902/2018. A coleta de dados foi realizada acessando os registros de documento institucional (prontuário eletrônico). Foram analisados os registros de relatórios de anamnese, hipótese diagnóstica e plano terapêutico singular (meta e estratégias), bem como das evoluções clínicas de 20 sessões de atendimento fonoaudiológico (3 sessões de avaliação e 17 de terapia) com descrição dos resultados diários.

\section{Resultados}

A criança de 3 anos e 4 meses (DN: 23/04/2013), compareceu ao serviço de Fonoaudiologia, acompanhada pelo pai e pela tia paterna, com a queixa de "atraso de fala" (sic pai). Os informantes referiram que a menor realizou programa de intervenção precoce entre 2 e 3 anos de idade em uma instituição em sua cidade natal, e encontrava-se matriculada em uma creche municipal desde os 3 anos.

De acordo com o relatório pediátrico, o parto (36 semanas) foi cesariano devido à hipertensão materna. A criança nasceu com importante edema de mãos e pés, com extensão para membros, associados a dismorfias, com APGAR de 5/10 (primeiro minuto) e 8/10 (no quinto minuto) e ingeriu o líquido meconial. Com 30 minutos de vida apresentou hipoglicemia de difícil controle sendo necessária a administração de vários pushs de glicose e soroterapia. Com 1 hora de vida, apresentou desconforto respiratório e necessidade de oxigênio $(\mathrm{O} 2)$.

Permaneceu na UTI por 13 dias, e neste período apresentou quadro sugestivo de sepse precoce, associada à plaquetopenia. Em decorrência do quadro foram ministrados hidrocortisona, ranitidina, ampicilina e gentamicina.

Foi submetida e aprovada em todos os exames neonatais (audição, visão e "teste do pezinho") e avaliada e acompanhada pela fonoaudióloga para estimulação da sucção não nutritiva e nutritiva, sendo a dieta administrada por via oral (aleitamento materno e mamadeira). Recebeu alta para a enfermaria após os 13 dias de internação. 
O diagnóstico genético de Síndrome de Turner foi confirmado ainda durante a gestação da mãe por meio do teste de amniocentese. Após o nascimento, em exame genético, foi evidenciada a monossomia completa do cromossomo X.

Os marcos do desenvolvimento motor da criança foram: controle de tronco por volta dos 11 meses, não engatinhou e começou a andar sem ajuda aos 14 meses.

Os informantes negaram patologias do ouvido e referiram comportamento auditivo adequado a idade. A respeito do desenvolvimento da linguagem, a criança possuía uma comunicação predominantemente gestual. Balbuciou por volta dos 2 anos e 9 meses. Por volta dos 3 anos falou as primeiras palavras ("tia“, "cocó", "papa" e "tchau”), porém sem expansão do vocabulário. Foi referido que a compreensão era adequada para ordens simples. Em relação ao simbolismo, criança gostava de brincar, mantinha o interesse na brincadeira, dando função a alguns objetos (como por exemplo, um carro de brinquedo).

Foram realizadas 3 sessões, de 40 minutos cada, para a avaliação das habilidades comunicativas, a compreensão verbal e os aspectos do desenvolvimento cognitivo, além de avaliação audiológica. Foram utilizados os seguintes instrumentos: Protocolo de Observação Comportamental - PROC (Zorzi \& Hage, 2004) e Avaliação do Desenvolvimento da Linguagem ADL (Menezes, 2004).

Quanto às habilidades de comunicação observou-se que a criança raramente apresentava intenção comunicativa, sendo que muitas vezes não mantinha contato visual. Iniciava e respondia raramente a interação, para ambos realizava gesto indicativo à ação e vocalizações não-articuladas, com função instrumental, regulatória (colocando brinquedos na mão da profissional, ou solicitando algum objeto por gestos indicativos e vocalizações). Não havia engajamento da menor na atividade dialógica.

Para as funções comunicativas, raramente solicitava objetos (quando solicitava, fazia uso de gestos indicativos e vocalizações, como por exemplo: "cocó” para uma miniatura de galinha e "tatá” para o brinquedo Senhor Batata); realizava protesto por meio de vocalizações, e somente quando um objeto de muito interesse para a mesma era retirado de sua mão; utilizava algumas expressões sociais, como "oi" e "tchau", porém apenas quando solicitada, ou como resposta ao interlocutor; não realizava a nomeação de objetos; não fazia comentários informativos; solicitou permissão por meio da expressão "me dá?", apenas quando a terapeuta lhe deu o modelo; e não realizava narrativa.

Os meios de comunicação eram predominantemente não verbais, com vocalizações não articuladas e articuladas com entonação da língua, porém com presença de palavras isoladas ("tchau”, "alô"); usava gestos não simbólicos elementares e convencionais. O nível de contextualização da linguagem referia-se somente à situação imediata e concreta. A criança respondia de maneira não sistemática a uma solicitação, comentário ou quando chamada, seja por vocalizações ou respostas motoras; compreendia algumas ordens simples ligadas ao contexto imediato e concreto, não acompanhadas de gestos (dar comidinha à boneca, atender ao telefone, abrir a bolsa, abrir a porta, fazer a boneca dançar), sendo que respondia de forma assistemática a algumas ordens (colocar panela no fogão, limpar pratinho) e não executava ordens complexas e fora do contexto imediato.

Quanto à forma de manipulação dos objetos, notou-se que a criança atuava de maneira diversificada sobre dois ou mais objetos ao mesmo tempo, relacionando-os (colocou a boneca no sofá para dormir, utilizou prato e colher em miniatura para dar comida à boneca, empilhou blocos, limpou o fogão com a esponja), o que caracterizava a transição entre os períodos sensório-motor e o pré-operatório.

A menor não realizou a imitação de gestos/movimentos visíveis ao corpo. Reproduziu palavras ("me dá" e "alô"). O desempenho da menor no PROC foi abaixo do esperado: a) Habilidades Comunicativas verbais e não verbais: pontuação 30 de 70 pontos; b) Compreensão verbal: 50 de 60 pontos; e c) desenvolvimento cognitivo: 19 de 70 pontos. O score total foi de 99 pontos. Para a idade de 3 anos, esperava-se pontuação mínima de 162 pontos e o desempenho foi inferior ao esperado para 2 anos era 137 pontos (Hage, Pereira \& Zorzi, 2012). 
Segundo os valores normativos, seu desempenho no ADL, tanto a nível emissivo quanto a nível receptivo foi semelhante ao desempenho de uma criança de 12 a 17 meses, estando abaixo do esperado para sua idade, com escore padrão global de 57, que de acordo com a classificação do ADL seria considerado um distúrbio severo de linguagem (escore padrão global abaixo de 69).

Quanto à motricidade orofacial, constatou-se que não havia alteração de palato duro e frênulo lingual. Foram evidenciadas alterações de mobilidade (para cima, para baixo e lateralidade) de lábios, língua e bochechas. A criança apresentou respiração mista, permanecendo com os lábios entreabertos durante grande parte dos atendimentos. Quanto a mastigação e deglutição foram testadas a consistência líquida (água) e sólida (bolacha doce) não sendo observadas alterações visíveis que comprometesse a dinâmica destas funções.

A avaliação audiológica realizada em campo livre evidenciou que a paciente possuía atenção, porém sem localização, com obtenção de um limiar assistemático de $30 \mathrm{~dB}$ para a atenção de tom warble e fala. Não foi possível realizar a imitanciometria (pois não aceitou a colocação de sonda) e foi indicada a realização de uma nova avaliação após um ano.

Com base nos dados de anamnese e nos achados de avaliação, a hipótese diagnóstica fonoaudiológica foi de Distúrbio de Linguagem e foi encaminhada para intervenção. Devido à fila de espera no Serviço, o processo terapêutico iniciou-se após aproximadamente 6 meses.

Foram realizadas 17 sessões de fonoterapia, com duração de 40 minutos cada e periodicidade semanal, cujo objetivo geral era desenvolver a linguagem oral. Durante o período foram definidas como estratégias a curto prazo: estimular as ações sensório-motoras, explorar o uso convencional dos objetos, linguagem receptiva e expressiva e orientação familiar.

Dessa forma, foram estimuladas ações sensório-motoras sobre os objetos (montar, desmontar, derrubar, esconder, empilhar, encaixar e procurar) com brinquedos de encaixe e peças de montar. Com objetos em miniatura de diferentes classes semânticas (utensílios de cozinha, casa, escola e cuidado diário) foi estimulada a nomeação destes e construção de frases simples, bem como o uso convencional destes objetos. A linguagem receptiva (compreensão de ordens simples e semicomplexas) foi estimulada no decorrer das sessões por meio de comandos e ordens relacionadas às atividades executadas e o ambiente da sala de atendimento como um todo. Observou-se maior interesse da criança nas atividades que envolveram a temática de utensílios de cozinha e de cuidado diário, onde houve maior interação entre estímulo-criança e criança-avaliador.

Durante todo o processo terapêutico foi estabelecido um vínculo de comunicação com os responsáveis para que as estratégias realizadas em sessão pudessem ser reproduzidas em domicílio. Para isso, durante o atendimento, os pais eram convidados a ficar na sala de atendimento para observarem e participarem da terapia. Ao final, eram repassados dados acerca do desempenho, ganhos observados e orientações fonoaudiológicas a serem reproduzidas no cotidiano da criança, bem como a resolução de possíveis dúvidas elencadas por estes.

Ao final das 17 sessões de terapia, foi realizada uma reavaliação com os mesmos testes utilizados na primeira avaliação, a fim de verificar os possíveis ganhos obtidos por meio da terapia, que serão descritos a seguir. Vale ressaltar que no momento da realização destes procedimentos a criança já apresentava 4 anos e 8 meses.

Para o PROC, nas habilidades comunicativas verbais e não-verbais apresentou função instrumental com solicitação de objetos, função de protesto, função interativa para expressões sociais, nomeação de objetos (classe semântica de animais, alimentos e utensílios de cozinha) e construção de frases simples, com pontuação de 50 pontos; na compreensão verbal, compreende ordens com até duas ações, com 25 pontos; e o aspecto do desenvolvimento cognitivo com melhora da organização e manipulação do brinquedo com função e imitação de gestos/expressões com 40 pontos. Totalizou 115 pontos, evidenciando melhora desde a avaliação (que era de 99 pontos), entretanto, ainda abaixo do padrão de normalidade do teste (162 pontos). 
No ADL, seu desempenho, tanto a nível emissivo quanto a nível receptivo, foi semelhante ao desempenho de uma criança de 2 anos e 6 meses a 11 meses, estando, portanto, abaixo do esperado. Comparando o resultado obtido com a tabela de normalidade, pode-se concluir que a criança anteriormente com distúrbio severo de linguagem passou a apresentar um distúrbio moderado de linguagem (escore padrão global abaixo de 89).

Além disso, foi realizada uma nova avaliação auditiva. Novamente, o resultado foi de um limiar assistemático de $30 \mathrm{~dB}$ para a atenção de tom warble e fala e devido à recusa da sonda, não foi possível a realização da imitanciometria. Entretanto, foi realizado exame de Potencial Evocado Auditivo de Tronco Encefálico (PEATE) com a criança sedada, apresentando latência absoluta e interpicos normais nas ondas I, III e V em 80dB bilateralmente, sugerindo adequada integridade do nervo auditivo e ausência de alteração retrococlear.

\section{Discussão}

A Síndrome de Turner tem sido estudada há aproximadamente 80 anos, entretanto, ainda há inúmeras lacunas referentes às manifestações e possibilidades de intervenção desta patologia, inclusive na Fonoaudiologia.

Um estudo bibliográfico pioneiro no Brasil levantou pesquisas publicadas entre 1938 e 2009 sobre o tema (Mandelli \&Abramides, 2012). Foram encontrados 23 artigos dos quais 07 abordavam sobre a audição, 06 sobre linguagem receptiva e/ou expressiva e praxia, 05 acerca de aspectos psicológicos e cognitivos, além de 28 referentes às manifestações clínicas em geral. Com base nesses achados, observou-se que as manifestações fonoaudiológicas na ST são pouco estudadas, sendo as manifestações audiológicas (perda de audição e otites) as mais recorrentes, ao contrário dos aspectos linguísticos (expressão e recepção) e práxicos.

Os distúrbios auditivos mais recorrentes nestes portadores são otite média de repetição, disfunção das trompas de Eustáquio, perdas auditivas condutivas durante a infância e perdas auditivas sensorioneurais a partir da adolescência, decorrente de uma possível alteração morfológica da cóclea (Oliveira, 2014). Neste caso, não foi possível realizar o exame de audiometria formal e imitanciometria, devido à idade da criança, o déficit de compreensão dos testes e a recusa destes. Entretanto, foi realizado o PEATE, resultando em presença das ondas I, III e V, contrariando o preconizado na literatura de que devido ao tratamento de reposição de estrógeno, há um aumento das latências interpicos III-V e I-V (Oliveira, 2014). Estes dados demonstram a importância da investigação e monitoramento audiológico, uma vez que os limiares e as funções auditivas podem apresentar piora e se agravar com o passar do tempo.

Quanto ao complexo craniofacial e à motricidade orofacial, a deficiência dos genes do cromossomo $\mathrm{X}$ têm influência direta sobre três partes anatômicas faciais - a base craniana, maxilar e mandíbula - causando crescimento irregular. Dentre as principais características orofaciais, destacam-se o palato ogival, mandíbula com menor espessura e tamanho e má oclusão dentária, além de diminuição de tônus e mobilidade de estruturas (língua, lábios e bochechas), importantes na execução de funções como respiração, mastigação e deglutição (Mandelli \&Abramides, 2012). No caso descrito, foi observada alteração de mobilidade de lábios, língua e bochechas, entretanto, sem alteração significativa para a mastigação e deglutição. Foi evidenciada alteração na respiração (mista), sendo que a criança permanecia com os lábios entreabertos para executar esta função.

Com base na literatura, não são esperadas alterações de linguagem em crianças com ST. A maioria dos resultados em testes neuro cognitivos, apontam que o QI verbal, subtestes de semelhanças verbais, compreensão verbal e vocabulário se encontraram dentro do padrão de normalidade, quando comparadas com indivíduos em desenvolvimento típico (Murphy, 2009).

Em relação ao desenvolvimento da linguagem, há evidências de que crianças em condições de nascimento adversas podem apresentar alterações em diversos subdomínios linguísticos (Constant, Silva e Zuanetti, 2017; Moretti, Kuroishi \& 
Mandrá, 2017). Por este fato, pode-se sugerir que o fato de a criança ter sido exposta a diferentes variáveis após o seu nascimento, pode também ter contribuído com o déficit destas habilidades abordadas no estudo.

Além disso, as produções científicas atuais apontam ainda para a relevância da estimulação em âmbito familiar e escolar principalmente para o processo de aquisição e desenvolvimento da linguagem oral (Carvalho, Lemos \& Goulart, 2016; Scopel, Souza \& Lemos, 2012). Sendo assim, evidencia-se a importância da participação da família e da escola no processo terapêutico com constante orientação por parte do fonoaudiólogo para que os aspectos estimulados em terapia sejam reproduzidos no cotidiano da criança e haja uma continuidade e linearidade do processo terapêutico.

\section{Conclusão}

A intervenção fonoaudiológica foi fundamental para a evolução das habilidades de comunicação (vocabulário emissivo e vocabulário receptivo), demonstrando a importância da participação do fonoaudiólogo na equipe multiprofissional de atendimento nestes casos.

Poucos estudos correlacionam a Síndrome de Turner e a Fonoaudiologia, especialmente na área de linguagem, o que evidencia a necessidade de novas publicações para um melhor embasamento teórico, clínico e prático frente a estes casos.

\section{Referências}

Alves C \& Oliveira CS. (2014). Perda auditiva em pacientes com síndrome de Turner: revisão da literatura. Braz. j. otorhinolaryngol, 80(3), 20-34.

Antunes A. M, Júlio-Costa, A \& Haase V. G. (2015). Variações cariótipas na Síndrome de Turner: uma análise do fenótipo cognitivo. Rev. Interinst. Psicol. (Online), 8(2):348-58.

Araújo C, Galera B. B, Galera M. F \& Medeiros S. F. (2010). Características clínicas e citogenéticas da síndrome de Turner na região Centro-Oeste do Brasil. Rev. Bras. Ginecol. Obstet, 32(8), 381-5.

Carvalho, A. J. A, Lemos, S. M. A \& Goulart, L. M. H. F. (2016). Desenvolvimento da linguagem e sua relação com comportamento social, ambientes familiar e escolar: revisão sistemática. $\operatorname{CoDAS,} 28$ (4): 1-11.

Constant, A. C. C, Silva, K \& Zuanetti, P. A. (2017) Risk factors for language development associated with prematurity. Audiol Commun Res, 22 (1): 1-7.

Giacheti, C. M. (2004). Fonoaudiologia e Genética: Estudos Contemporâneos. Tratado de Fonoaudiologia. Editora Roca, 52-9.

Gravholt, C. H., Viuff, M. H., Brun, S., Stochholm, K., \& Andersen, N. H. (2019). Turner syndrome: mechanisms and management. Nature reviews. Endocrinology, 15(10), 601-614.

Hage, S. R. V, Pereira, T. C \& Zorzi, J. L. (2012) Protocolo de Observação Comportamental - PROC: valores de referência para uma análise quantitativa. Rev. CEFAC, 14(4):677-90.

Hutaff-Lee, C., Bennett, E., Howell, S., \& Tartaglia, N. (2019). Clinical developmental, neuropsychological, and social-emotional features of Turner syndrome. American journal of medical genetics. Part C, Seminars in medical genetics, 181(1), $126-134$.

Kruszka, P., \& Silberbach, M. (2019). The state of Turner syndrome science: Are we on the threshold of discovery?. American journal of medical genetics. Part C, Seminars in medical genetics, 181(1), 4-6.

Mandelli, S. A \&Abramides, D. V. M. (2012). Manifestações clínicas e fonoaudiológicas na Síndrome de Turner: estudo bibliográfico. Rev. CEFAC, 14(1):146-55.

Marzelli, M. J. (2011). Neuroanatomical spatial patterns in Turner syndrome. Neuroimage, 55(1):439-47.

Menezes, M. L. N. (2004). ADL - Avaliação do desenvolvimento da linguagem. Book Toy.

Moretti, T. C. F, Kuroishi, R. C. S., \& Mandrá, P. P. (2017). Vocabulário de pré-escolares com desenvolvimento típico de linguagem e variáveis socioeducacionais. CoDAS, 2017, 29 (1): 1- 10.

Murphy, M. M. Language and literacy in Turner syndrome. (2009). Top Lang Disorders, 29(2):187-94.

Oliveira, C. S. (2014). Avaliação dos potenciais auditivos de tronco encefálico e das emissões otoacústicas transientes em pacientes com Síndrome de Turner [tese]. Salvador (BA): Universidade Federal da Bahia - UFBA.

Oliveira, A. W., Freiberger L, Fernandes R. D, Marcelino T. F, Da Rosa, L., \& Correa M. (2005). Síndrome de Turner: relato de caso. Arquivos Catarinenses de Medicina, 34(3):76-9. 
Research, Society and Development, v. 10, n. 15, e59101522563, 2021

(CC BY 4.0) | ISSN 2525-3409 | DOI: http://dx.doi.org/10.33448/rsd-v10i15.22563

Scopel, R. R., Souza, V. C., \& Lemos, S. M. A. (2012). A influência do ambiente familiar e escolar na aquisição e desenvolvimento da linguagem: revisão de literatura. Rev. Cefac, 14 (04): 12-20.

Temple, C. M. Oral fluency and narrative production in children with Turner's syndrome. (2002). Neuropsychologia, 40(8):1419-27.

Zorzi, J. L., \& Hage, S. R. V. (2004). PROC - Protocolo de observação comportamental: avaliação de linguagem e aspectos cognitivos infantis. Pulso Editorial. 